\title{
Extradural Middle Fossa and Transcavernous Approach for Resection of Trigeminal Neurinoma at Lateral Cavernous Sinus
}

\author{
Hideaki Ono $^{1}$ Seiei Torazawa ${ }^{1,2}$ Takeo Tanishima ${ }^{1}$ Akira Tamura ${ }^{1}$ Isamu Saito ${ }^{1}$
}

${ }^{1}$ Department of Neurosurgery, Fuji Brain Institute and Hospital, Shizuoka, Japan

2 Department of Neurosurgery, The University of Tokyo Hospital, Tokyo, Japan

J Neurol Surg B Skull Base 2022;83(suppl S3):e659-e660.
Address for correspondence Hideaki Ono, MD, PhD, Department of Neurosurgery, Fuji Brain Institute and Hospital, 270-12, Sugita, Fujinomiya-City, Shizuoka, 418-0021, Japan

(e-mail: hideono-tky@umin.ac.jp).

\begin{abstract}
Keywords

- trigeminal neurinoma

- cavernous sinus

- extradural approach

- middle fossa approach

- transcavernous approach

We present a 52-year-old male case of right trigeminal neurinoma at lateral cavernous sinus. The tumor was $40 \mathrm{~mm}$ in maximum diameter, obviously compressed temporal lobe and encased internal carotid artery. Extradural middle fossa and transcavernous approach was applied and the tumor was resected via Parkinson's triangle. This approach enabled safe and effective tumor resection, sufficient visualization, and operative field (-Figs. 1 and 2). We performed dissection of the tumor from trigeminal nerve, tentorium, and middle fossa and resect the tumor around internal carotid artery sufficiently. Postoperative course was good without any new neurological deficit. This surgical method is considered safe and effective for the resection of the tumor at lateral cavernous sinus.

The link to the video can be found at: https://youtu.be/2ekulLIgEuo.
\end{abstract}

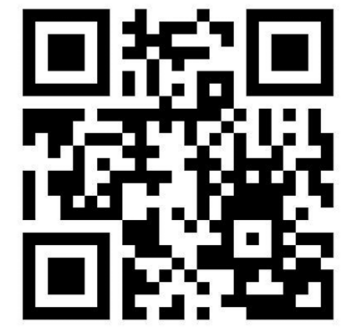

received

April 1, 2020

accepted after revision

September 23, 2021

published online

November 23, 2021
Conflict of Interest

None declared.

www.thieme.com/skullbasevideos

www.thieme.com/jnlsbvideos
DOI https://doi.org/

10.1055/s-0041-1736630.

ISSN 2193-6331.

\footnotetext{
(C) 2021. The Author(s).

This is an open access article published by Thieme under the terms of the Creative Commons Attribution-NonDerivative-NonCommercial-License, permitting copying and reproduction so long as the original work is given appropriate credit. Contents may not be used for commercial purposes, or adapted, remixed, transformed or built upon. (https://creativecommons.org/ licenses/by-nc-nd/4.0/)

Georg Thieme Verlag KG, Rüdigerstraße 14, 70469 Stuttgart, Germany
} 


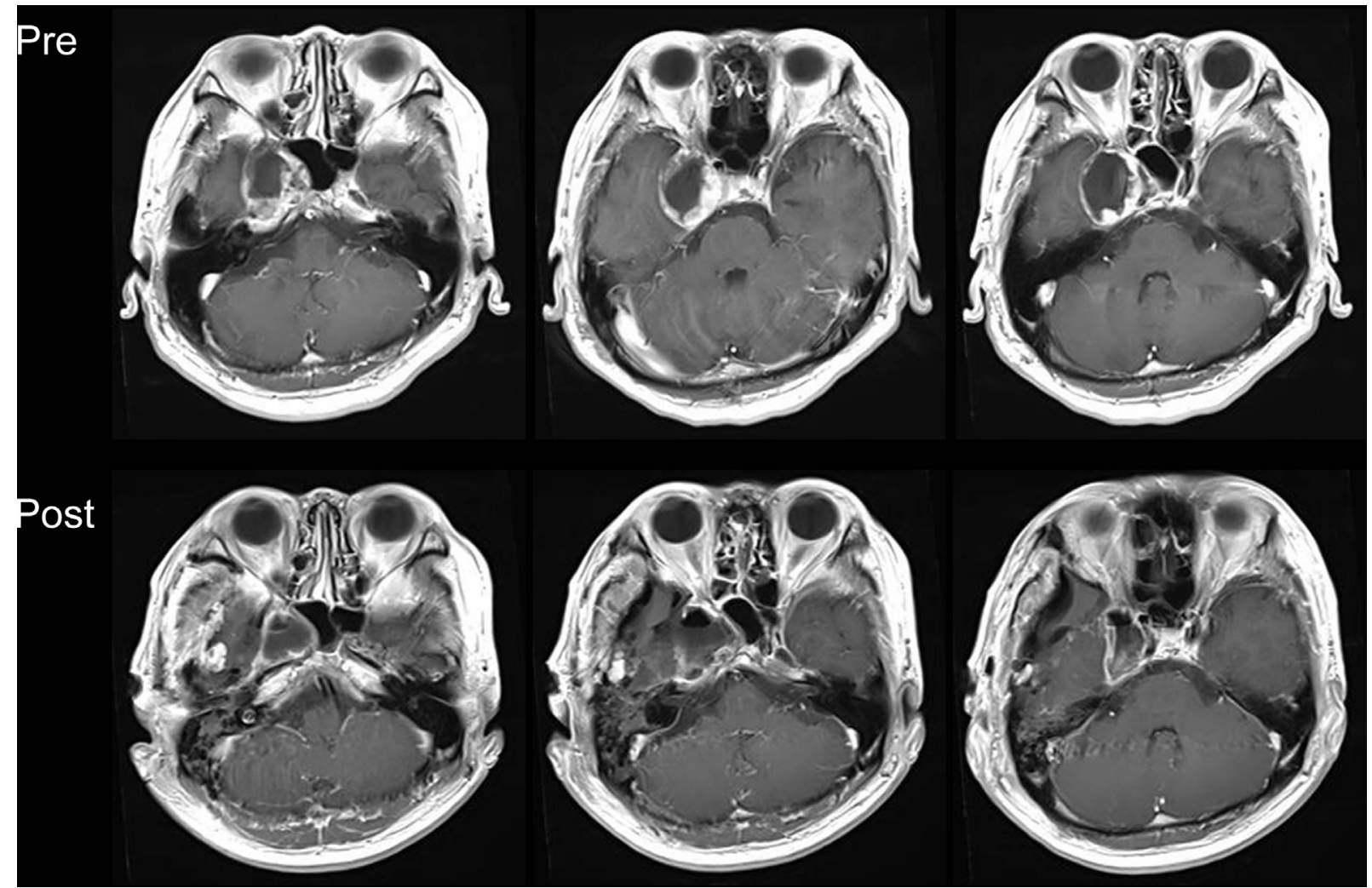

Fig. 1 Pre- and postoperative magnetic resonance imaging.

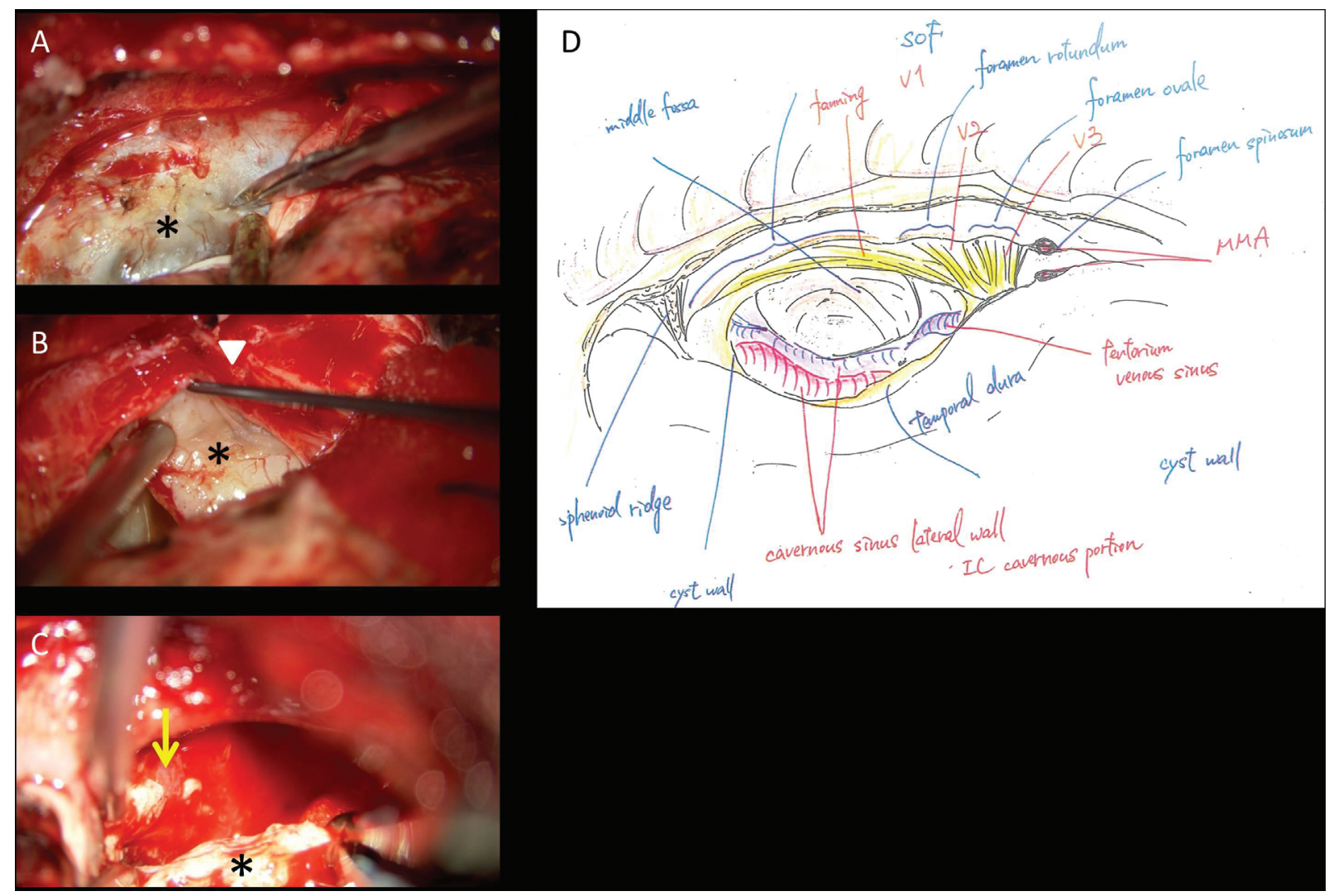

Fig. 2 Intraoperative images and schema. (A) The tumor capsule is incised, (B) detachment from trigeminal nerve, and (C) tumor surrounding internal carotid artery is resected (*tumor; arrowhead: trigeminal nerve; arrow: internal carotid artery). (D) Schema of the final operative field (V1: ophthalmic nerve, V2: maxillary nerve, V3: mandibular nerve). 